\title{
Psychiatry: no longer in dissent?
}

Medicine thrives on dissent. Of all the medical disciplines, psychiatry seems to generate the highest level of dissent, both from inside and outside the profession: no other medical discipline, for example, has some of its own members consistently argue that its very foundations are rooted in a series of harmful myths (Szasz, 1974, 2003). The best responses to this type of criticism identify the core concerns of the critic, dissect out the most relevant arguments and develop ways to integrate useful suggestions with existing knowledge, so as to advance the field in a pragmatic, sensible and evidence-based fashion. Such constructive responses to controversy are rare.

Thirty years ago, Dr Anthony Clare produced what was arguably the most comprehensive and constructive commentary on controversial issues in psychiatry to be published in a generation, in his now-classic book, Psychiatry in Dissent: Controversial Issues in Thought and Practice (Clare, 1976). At that time, Dr Clare was a research worker at the Institute of Psychiatry and honorary senior registrar at the Bethlem and Maudsley Hospitals, London.

Psychiatry in Dissent was a highly ambitious book, aimed at providing a rational counter-argument to the most trenchant critics of psychiatry in the 1970s, and establishing a reasoned middle ground between the antipsychiatry movement and the emergent school of biological psychiatry. Psychiatry in Dissent proved to have an enormous impact: not only did it provide a reasoned response to critics of psychiatry in the 1970s but it also provided intellectual inspiration to a generation of psychiatric trainees (e.g. Wessely, 2002). It remains in print today, as part of Routledge's 'International Behavioural and Social Sciences Library: Classics from the Tavistock Press' (Clare, 2001). The purpose of this paper is to provide a brief overview of the contemporary relevance of Psychiatry in Dissent on the 30th anniversary of its publication.

\section{The myth of the myth of mental illness}

Clare started his book by focusing on the very concept of mental illness and addressing the criticisms of psychiatric diagnosis and classification presented by, among others, Szasz, Laing and Foucault. Clare acknowledged the problems presented by psychiatric classification and explored several diagnostic dilemmas that illustrated the limitations of existing systems, including the case of a 16 year-old boy who was described as aggressive, disruptive and remorseless, but did not show signs of affective or psychotic disturbance. Clare noted that in this case most psychiatrists would consider a diagnosis of personality disorder, but 'where disagreement would appear would be over the question of whether such a person is actually ill. Disturbed he may be, unhappy even, but is he ill?' (Clare, 1976, p. 20). Today, the values of specific systems of psychiatric classification continue to be debated within the profession. Indeed, these issues may well have become more acute in recent years, following the emergence of novel diagnostic categories such as 'severe dangerous personality disorder' whose societal and legal convenience may appear substantially to exceed their clinical provenance (White, 2002).

Clare's explicit defence of psychiatric classification throughout Psychiatry in Dissent is a reflection of the turbulent times in which the book first appeared, when psychiatry was facing radical criticism in relation to such fundamental issues as the validity of the concept of mental illness and the usefulness of psychiatric classification. These debates, once a dominant feature of psychiatric discourse, have over the past 30 years become more measured but at the same time more peripheral. This is attributable to a number of factors including the development of more fine-grained atheoretical classification systems that are designed as diagnostic tools rather than absolute systems, and the acknowledgement that many advances in psychiatric research have depended upon the delineation and study of discrete syndromic entities, which have helped to optimise the reliability and comparability of research findings across different centres.

Another defence offered by Clare was that, contrary to the claims of the anti-psychiatry movement, clinically based classification systems actually help to protect the individual from being labelled mentally ill for purposes of societal or political convenience. As Clare wrote, 'What protects the dissident, the deviant, and the outsider from being labeled "mentally ill" is not the psychiatrist who does not believe in psychiatric classifications . . . but rather the psychiatrist who acknowledges that people can suffer from serious mental disturbances, that the symptoms of these can be grouped and defined in such a way as to produce a reasonable degree of agreement as to their validity and reliability, and that those people who do not show such symptoms cannot be classified as mentally ill, whatever society may say or do' (Clare, 1976, p. 156). In the 30 years since Psychiatry in Dissent first appeared, the importance of Clare's defence of clinical classification has been demonstrated again and again, particularly in the context of the alleged labelling of political dissidents as mentally ill in the former Soviet Union in the 1970s and 1980s (Bloch \& Reddaway, 1984) and more recently in the People's Republic of China (Munro, 2000).

\section{Dichotomies, discussions and other unfinished business}

Although generally defending the usefulness of the concept of disease entities, Clare warned 'it is probably a mistake to conceptualise normality and madness as 
dichotomous, that is to say as states of mind, inhabitation of one necessarily mitigating against the other. Rather they are best thought of as opposite ends of a continuum, a continuum on which most of us find ourselves positioned in that grey and shady area between the two opposing poles' (Clare, 1976, p. 32). When these words were written, the idea of a continuum of illness had a long history in relation to affective disorders, but the subsequent 30 years have produced considerable evidence of another, less obvious, continuum in relation to the psychoses, based on increasing evidence of psychotic and quasi-psychotic phenomena in the general population who do not meet the formal criteria for psychotic illness (Verdoux \& Van Os, 2002).

Focusing further on the ways in which clinicians conceptualise psychological disorders, Clare went on to emphasise 'it is no longer possible to identify a state, reaction or disease as physical or psychological. An emotion, such as phobic anxiety . . can be described in psychological terms as a "fear" or a "terror" or in the physiological language of autonomic nervous system function and hormonal secretion. Forced by the considerations of pragmatism and convenience to opt for one or other of the two languages, somatic and psychological, with which to describe psychiatric phenomena, psychiatrists create the unfortunate impression that there are two distinct kinds of disease - organic and functional' (Clare, 1976, p. 33). This misleading distinction between 'psychological' and 'physical' phenomena remains as unhelpful today as it was in 1976, and it still supports a false dichotomy between mind and brain that continues to distort perceptions of mental illness (Andreason, 2001).

Clare does not shy away from contrary arguments or awkward positions, and does not hesitate to acknowledge the relative merits of conflicting approaches to different issues. Today, there may be less fundamental dissent about issues such as the validity of the concept of mental illness or the overall usefulness of psychiatric classification, but there remains an active critical psychiatry movement whose ideas continue to challenge and illuminate difficulties in these areas (for a recent review see Thomas \& Bracken, 2004). Moreover, there is increased concern about different, more specific issues, such as the effects of the pharmaceutical industry on psychiatric practice (Healy \& Cattell, 2003), or the merits of particular diagnostic categories (Hsieh \& Kirk, 2003). Clearly, the reasoned, logical and balanced approach to conflict, as demonstrated in Psychiatry in Dissent, is still as necessary and relevant as ever.

Interestingly, even though some of the themes of conflict have changed over the past 30 years, many of the topics explored in Psychiatry in Dissent remain very relevant today, albeit in different ways. For example, Clare's discussion of psychosurgery in children as young as 5 years now serves as a strong defence of contemporary models of evidence-based medicine, even though Clare was writing some 20 years before the recurrent concept of evidence-based medicine enjoyed its most recent renaissance (Sackett et al, 1996). Clare's comments on schizophrenia serve as a poignant reminder of how little has changed, as it broadly remains the case that 'for all the advances, in understanding and in treatment, the condition remains a baffling and enigmatic one, a harrowing experience for the individual sufferer, and a challenge to the ingenuity and skill of those intent on unlocking its secrets' (Clare, 1976, pp. 214-215).

In an era when much psychiatric debate is characterised by a 'sea of rhetorical vituperation' (Clare, 1976, p. 306), and psychiatric training is increasingly based on vapid multi-author texts, Psychiatry in Dissent serves as an affirmation of the ability of the thoughtful individual psychiatrist to make sense of the controversies that rage within psychiatry. It is also a testament to the importance of applying recent advances in thought and practice to the development of models of patient care that are equitable, acceptable, evidence-based and, most of all, effective.

\section{Declaration of interest}

None.

\section{Acknowledgements}

Quotations from Psychiatry in Dissent: Controversial Issues in Thought and Practice (Clare, 1976) are reproduced by kind permission of Routledge and with the agreement of Professor Anthony Clare.

\section{References}

ANDREASON, N. (2001) Brave New Brain: Conquering Mental Illness in the Era of the Genome. Oxford: Oxford University Press

BLOCH, S. \& REDDAWAY, P. (1984) Soviet Psychiatric Abuse: The Shadow Over World Psychiatry. London: Gollancz.

CLARE, A.W. (1976) Psychiatry in Dissent: Controversial Issues inThought and Practice. London: Tavistock.

CLARE, A.W. (2001) Psychiatry in Dissent: Controversial Issues inThought and Practice (International Behavioural and Social Sciences Library: Classics from theTavistock Press). London: Routledge.

HEALY, D. \& CATTELL, D. (2003) Interface between authorship, industry and science in the domain of therapeutics. British Journal of Psychiatry, 183, 22-27.

HSIEH, D. K. \& KIRK, S. A. (2003) The effect of social context on psychiatrists' judgements of adolescent antisocial behaviour. Journal of Child Psychological Psychiatry, 44, 877-887. MUNRO, R. (2000) Judicial psychiatry in China and its political abuses.

Columbia Journal of Asian Law, 14, $1-125$.

SACKETT, D. L., ROSENBERG, W. M. C. MUIR GRAY, J. A., et al (1996) Evidence based medicine: what it is and what it isn't. BMJ, 312, 71-72.

SZASZ,T. S. (1974) The Myth of Mental Illness: Foundations of aTheory of Personal Conduct (2nd edn). New York: Harper \& Row.

SZASZ,T. S. (2003) The psychiatric protection order for the "battered mental patient". BMJ, 327, 1449-1451. THOMAS, P. \& BRACKEN, P. (2004) Critical psychiatry in practice. Advances in Psychiatric Treatment, 10, 361-370.

VERDOUX, H. \& VAN OS, J. (2002) Psychotic symptoms in non-clinical populations and the continuum of psychosis. Schizophrenia Research, 54, 59-65.

WESSELY, S. (2002) Ten books: chosen by SimonWessely. British Journal of Psychiatry, 181, 81-84.

WHITE, S. M. (2002) Preventive detention must be resisted by the medical profession. Journal of Medical Ethics, 28 95-98.

Brendan D. Kelly Senior Lecturer in Psychiatry, Department of Psychiatry, University College Dublin, Mater Misericordiae University Hospital, 62/63 Eccles Street, Dublin 7, Ireland,email: brendankelly35@gmail.com, Larkin Feeney Senior Registrar in Psychiatry, Department of Psychiatry, St Vincent's Hospital, Fairview, Dublin 3, Ireland. 